\title{
DAMPAK ILMU PENGETAHUAN TEKNOLOGI TERHADAP IMAN DAN TAKWA MAHASISWA
}

\author{
Sumiati $^{1}$, Sitti Satriani Is ${ }^{2}$ \\ ${ }^{* 1}$ Pendidikan Agama Islam Fakultas Agama Islam| Unismuh Makassar \\ ${ }^{* 2}$ Pendidikan Agama Islam Fakultas Agama Islam| Unismuh Makassar
}

\begin{abstract}
ABSTRAK
Sains dan teknologi mengalami perkembangan yang begitu pesat bagi kehidupan manusia. Dalam setiap waktu para ahli dan ilmuwan terus mengkaji dan tolok ukur era modern ini adalah sains dan teknologi. Sains dan teknologi meneliti sains dan teknologi sebagai penemuan yang paling canggih dan modern. Keduanya sudah menjadi simbol kemajuan pada abad ini. Oleh karena itu, apabila ada suatu bangsa atau negara yang tidak mengikuti perkembangan sains dan teknologi, maka bangsa atau negara itu dapat dikatakan negara yang tidak maju dan terbelakang. Islam adalah satu-satunyanya agama samawi yang memberikan perhatian besar terhadap ilmu pengetahuan. Islam tidak pernah mengekang umatnya untuk maju dan modern. Justru Islam sangat mendukung umatnya untuk melakukan research dan bereksperimen dalam hal apapun, termasuk sains dan teknologi. Bagi Islam sains dan teknologi adalah termasuk ayat-ayat Allah yang perlu digali dan dicari keberadaannya. Ayat-ayat Allah yang tersebar di alam semesta ini, dianugerahkan kepada manusia sebagai khalifah di muka bumi untuk diolah dan dimanfaatkan dengan sebaik-baiknya.
\end{abstract}

Kata Kunci: Ilmu PengetahuanTeknologi, Iman dan Takwa

\begin{abstract}
Science and technology have developed so rapidly for human life. In every time the expert and scientist continue to study and benchmarks of this modern era science and technology. Science and technology examine science and technology as the most sophiscated and modern. Both have become a symbol of progress in this century. Therefore, if there is a nation or country that does not follow the development of science and technology, then the nation or country can be said that the country is not advanced and backward. Islam is the only divine religion that gives great attention to science. Islam never forbide Moslem to advance and modern. Otherwise Islam strongly support Moslem commiting research and experiment in all cases including science and technology. For Islam science and technology are verses of Allah that need to be investigated and looked for its exsitance. The verses of Allah spread in the world, given for human as a leader of world to be processed and utilized as well as possible.
\end{abstract}

Keywords: Science of Technology, Faith and Piety 


\section{PENDAHULUAN}

Dunia pendidikan modern telah mengalami kemajuan yang sangat pesat seirama dengan tuntutan perkembangan dunia global. Hal itu dapat dilihat dari tawaran-tawaran program yang disodorkan oleh lembaga-lembaga pendidikan, baik yang berhubungan dengan perangkat keras (hard ware) maupun perangkat lunak (soft ware). Kemajuan pesat jelas menimbulkan problem baru bagi dunia pendidikan yang kurang siap dalam memberikan respon terhadap perkembangan tersebut. Bagi dunia pendidikan Islam akan menimbulkan permasalahan yang semakin kompleks bilamana dalam kenyataannya institusi pendidikan Islam dan tenaga pengajar selalu terlambat dalam memenuhi tuntutan perkembangan zaman. Keterlambatan itu menyangkut kemampuan dalam mempersiapkan sarana yang berhubungan dengan perangkat keras dan kemampuan sumber daya para dosen yang handal.

Perguruan tinggi Universitas Muhammadiyah Makassar adalah merupakan perguruan tinggi swasta yang mempunyai sekitar 45.000 mahasiswa yang terbagi dari beberapa fakultas dan jurusan, namun kesemuanya berada di bawah payung Agama yaitu Agama Islam dengan berdasar pada lingkup kemuhammadiyahan dalam meyakini keagungan Allah SWT dan Sunnah Rasulullah Saw. Bagi mahasiswa Unismuh yang menjadi persyaratan mutlak adalah beragama Islam dan mematuhi segala aturan yang ada di perguruan tinggi tersebut sesuai dengan aturan dalam lingkup Muhammadiyah. Dan khususnya di Fakultas Agama Islam mahasiswa memiliki kemampuan membaca alQur'an sudah lancar dan sudah fasih dalam membedakan huruf maupun harakat dalam membaca huruf-huruf dalam al-Qur'an.

Akan tetapi karena peradaban Barat moderen dan postmodern saat ini memang memperlihatkan kemajuan dan kebaikan kesejahteraan material yang seolah menjanjikan kebahagian hidup bagi umat manusia. Namun karena kemajuan tersebut tidak seimbang, pincang, lebih mementingkan kesejahteraan material bagi sebagian individu dan 
sekelompok tertentu negara-negara maju (kelompok G-8) saja dengan mengabaikan, bahkan menindas hakhak dan merampas kekayaan alam negara lain dan orang lain yang lebih lemah kekuatan iptek, ekonomi dan militernya, maka kemajuan di Barat melahirkan penderitaan kolonialismeimperialisme (penjajahan) di Dunia Timur \& Selatan. Kemajuan Iptek di Barat, yang didominasi oleh pandangan dunia dan paradigma sains (Iptek) yang positivistik-empirik sebagai anak kandung filsafat-ideologi materialisme-sekuler, pada akhirnya juga telah melahirkan penderitaan dan ketidakbahagiaan psikologis/ruhaniah pada banyak manusia baik di Barat maupun di Timur.

Kenyataan memprihatikan ini sangat ironis. Umat Islam yang mewarisi ajaran suci Ilahiah dan peradaban dan Iptek Islam yang jaya di masa lalu, justru kini terpuruk di negerinya sendiri, yang sebenarnya kaya sumber daya alamnya, namun miskin kualitas sumberdaya manusianya (pendidikan dan Ipteknya). Ketidakadilan global ini terlihat dari fakta bahwa $80 \%$ kekayaan dunia hanya dikuasai oleh 20
$\%$ penduduk kaya di negara-negara maju. Sementara $80 \%$ penduduk dunia di negara-negara miskin hanya memperebutkan remah-remah sisa makanan pesta pora bangsa-bangsa negara maju. Islam, sebagai agama penyempurna dan paripurna bagi kemanusiaan, sangat mendorong dan mementingkan umatnya untuk mempelajari, mengamati, memahami dan merenungkan segala kejadian di alam semesta. Berbeda dengan pandangan dunia Barat yang melandasi pengembangan Ipteknya hanya untuk kepentingan duniawi yang 'matre' dan sekular, maka Islam mementingkan pengembangan dan penguasaan Iptek untuk menjadi sarana ibadahpengabdian Muslim kepada Allah swt dan mengembang amanat Khalifatullah di muka bumi untuk berkhidmat kepada kemanusiaan dan menyebarkan rahmat bagi seluruh alam (Rahmatan lil 'Alamin).

\section{METODE PENELITIAN}

Metode yang digunakan dalam penelitian ini adalah metode deskriptif kualitatif. Penelitian deskriptif merupakan penelitian yang bertujuan menggambarkan suatu kondisi atau 
fenomena pendidik tidak memilahmilah atau mencari faktor-faktor atau variabel tertentu. Adapun Teknik yang digunakan dalam penelitian ini, yaitu:

\section{Studi Kepustakaan}

Pengumpulan data pertama-tama dilakukan melalui pengkajian literatur untuk mengungkapkan teori-teori yang relevan dengan topik penelitian

\section{Wawancara}

Wawancara yang dimaksud adalah Wawancara dengan model percakapan kedua belah pihak. Dalam konteks penelitian ini, peneliti merupakan pewawancara dengan mewawancarai para pihak yang dianggap memiliki keterkaitan dengan penelitian ini, yakni; Pemerintah, tokoh masyarakat, masyarakat biasa.

\section{HASIL DAN PEMBAHASAN PENELITIAN}

\section{Perkembangan Ilmu Pengetahuan dan Teknologi (IPTEK)}

Pengetahuan adalah segala sesuatu yang diketahui manusia melalui tangkapan pancaindera, intuisi dan firasat, sedangkan ilmu adalah pengetahuan yang sudah diklasifikasi, diorganisasi, disistematisasi, dan diinterpretasi sehingga menghasilkan kebenaran obyektif, sudah diuji kebenarannya, dan dapat diuji ulang secara ilmiah. Secara etimologis kata ilmu berarti kejelasan. Kata ilmu dengan berbagai bentuknya terulang 854 kali dalam Al-Qur'an. Kata ini digunakan dalam arti proses pencapaian pengetahuan dan obyek pengetahuan sehingga memperoleh kejelasan. Sedangkan istilah teknologi merupakan produk ilmu pengetahuan. Dalam sudut pandang budaya, teknologi merupakansalah satu unsur budaya sebagai hasil penerapan praktis dari ilmu pengetahuan. Meskipun pada dasarnya teknologi juga memiliki karakteristik, obyektif dan netral, dalam situasi tertentu teknologi tidak netral karena memiliki potensi untuk merusak dan potensi kekuasaan. Teknologi dapat membawa dampak positif berupa kemajuan dan kesejahteraan bagi manusia, juga sebaliknya dapat membawa dampak negatif berupa ketimpanganketimpangan dalam kehidupan manusia dan lingkungannya yang berakibat kehancuran alam semesta. 
Netralitas teknologi dapat digunakan untuk kemanfaatan sebesar-besarnya bagi kehidupan manusia dan atau digunakan untuk kehancuran manusia itu sendiri.

Oleh sebab itu, istilah pengetahuan dan ilmu dipahami oleh masyarakat luas menjadi satu istilah baku yaitu ilmu pengetahuan atau sains, istilah ini dapat didefinisikan sebagai himpunan pengetahuan manusiayang dikumpulkan melalui suatu proses pengkajian dan dapat diterima oleh rasio, dapat dinalar. Jadi ilmu pengetahuan dapat dikatakan himpunan rasionalisasi kolektif insani. Secara singkat sains dapat diartikan sebagai pengetahuan yang sistematis (science is systematic knowledge). Dalam pemikiran sekuler, sains mempunyai tiga karakteristik yaitu obyektif, netral dan bebas nilai, sedangkan dalam pemikiran Islam sains tidak boleh bebas dari nilai-nilai, baik nilai lokal maupun nilai universial.

Sebab teknologi itu diibaratkan dua mata pisau dalam segala aktivitas manusia, maksudnya adalah apabila pisau dipergunakan untuk menusuk orang berarti fungsinya untuk kejahatan tapi jika pisau ini dipergunakan sesuai fungsinya yang benar maka tentu saja akan bermanfaat. Demikian pula dengan teknologi yang semakin berkembang di jaman sekarang. Apabila dipergunakan secara bijak maka manfaatnya lebih banyak daripada mudharatnya. Oleh sebab itu jika iptek dipergunakan dan diimbangi dengan imtaq maka tentu hasilnya akan berbeda dengan menggunakan teknologi tanpa ada aturannya.

Berbicara tentang iptek tentu tidak terlepas dari budaya yang ada di tengah-tengah masyarakat yang berlaku di tiap-tiap negara dan bangsa dan secara spesifik yang berlaku di tiap daerah. Di dalam suatu budaya atau kultur sesuatu bangsa, sistem nilai merupkan landasan atau tujuan dari kegiatan sehari-hari yang menentukan dan mengarahkan bentuk, corak, intensitas, kelenturan (flexible), perilaku seseorang atau sekelompok orang, sehinga menghsilkan suatu masyarakat yang harmonis, aman dan sentosa seperti halnya pribadi mukmin yang hatinya selalu merasa aman dan damai karena berkata dan bertingkah laku yang benar. Maka apabila iptek 
dipergunakan sesuai dengan yang seharusnya dengan kata lain tidak mengunakan untuk hal-hal yang dapat mengganggu kepentingan dan ketenangan orang lain, tentunya kehidupan akan berjalan aman dan damai. Sebagaimana dalam firman Allah dijelaskan:
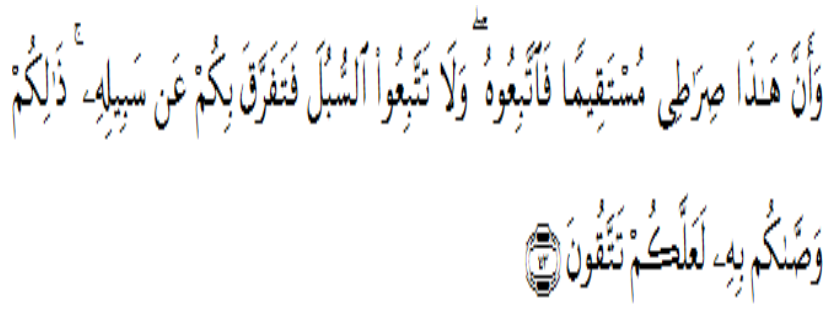

Artinya:

"Dan bahwa (yang kami perintahkan) ini adalah jalanku yang lurus, maka ikutilah dia; dan janganlah kamu mengikuti jalan-jalan (yang lain), karena jalan-jalan itu mencerai-beraikan kamu dari jalanNya. Yang demikian itu diperintahkan Allah kepadamu agar kamu bertaqwa." (Q.S. Al-An'am: 153).

Jadi makna yang terkandung dalam surah Al-An'am ayat 153 di atas menunjukkan bahwa janganlah memilih jalan yang salah atau dengan kata lain jangan melakukn sesuatu yang tidak sesuai dengan ajaran agama yang benar di yakini selain dari Allah SWT. Kemudian berdasarkan hasil wawancara dari salah seorang mahasiswa mengatakan bahwa:

"Kehadiran iptek di tengahtengah dunia pendidikan sangat meresahkan apabila tidak disikapi dengan bijak, karena terkadang memberikan kesan dari sikap dan tingkah laku dari generasi jaman sekarang memberikan gambaran kalau teknologi bisa menjawab segala kebutuhan dan keingintahuan dari semua hal. Sehingga menumbuhkan kebiasaan menunda waktu salat karena sudah terlalu sibuk bermain FB, WA, Line ataupun hal lainnya. Inilah yang dikhawatirkan seolah menghambakan dirinya kepada teknologi daripada kepada sang pencipta semesta alam”.

Apabila ditelaah dengan baik pernyataan dari salah seorang mahasiswa Unismuh tersebut, dapat dipahami bahwa kehadiran iptek dalam dunia pendidikan akan dipahami secara umum dapat merusak moral generasi, tetapi apabila difungsikan untuk hal yang bermanfaat maka kekhawatiran tersebut tentu akan berkurang. Meskipun demikian sangat disadari 
bahwa pengaruhnya lebih banyak dari sisi negatifnya. Sebab di khawatirkan bahwa ke depanya apabila manusia tidak memiliki Tuhan yang akan disembah, maka bisa jadi manusia akan mempertuhankan teknologi dengan pertimbangan bahwa apalagi yang tidk bisa ditemukan dalam teknologi, semua yang ingin diketahui sudah ada dalam internet, itulah kedangkalan dari cara pandang generasi dalam menyikapi kehadiran teknologi dalam kehidupannya.

Tingkat Keimanan dan Ketakwaan Mahasiswa Fakultas Agama Islam

Keimanan dan ketaqwaan merupakan core tujuan pendidikan nasional. Untuk mencapai tujuan tersebut, lembaga pendidikan dalam hal ini perguruan tinggi, yang merupakan salah satu wahana yang sangat efektif untuk mencapai tujuan pendidikan tersebut, dengan alasan karena melalui proses pendidikan di sekolah dan perguruan tinggi peserta didik/mahasiswa akan memperoleh bukan saja aspek pengetahuan dan keterampilan, tetapi juga pembentukan sikap yang mulia. Dalam rangka peningkatan keimanan dan ketakwaan mahasiswa tentu dengan melalui lembaga pendidikan. Direktorat Jenderal Manajemen Pendidikan Dasar dan Menengah telah mengembangkan lima strategi, yakni (1) optimalisasi pelaksanaan Pendidikan Agama Islam, (2) integrasi IPTEK dan IMTAQ dalam proses pembelajaran, pelaksanaan kegiatan ekstra kurikuler berwawasan IMTAQ, (4) penciptaan situasi yang kondusif dalam kehidupan sosial di sekolah, dan (5) melaksanakan kerjasama antara sekolah dengan orangtua dan masyarakat.

Oleh sebab itu, dalam pandangan Islam, antara agama, ilmu pengetahuan dan teknologi memiliki hubungan yang harmonis yang terintegrasi kedalam suatu sistem yang disebut Dinul Islam. Didalamnya terkandung tiga unsur pokok, yaitu; akidah, syari'ah, dan akhlak. Dengan kata lain iman, ilmu dan amal salih. Islam merupakan ajaran agama yang sempurna. Kesempurnaannya dapat tergambar dalam keutuhan inti ajarannya. Ada tiga inti ajaran Islam yaitu Iman, Islam dan Ikhsan. Ketiga inti ajaran itu terintegrasi didalam 
sebuah sistem ajaran yang disebut iman, ilmu dan amal merupakan satu Dinul Islam. Dalam QS 14 (Ibrahim): kesatuan yang utuh tidak dapat 24-25 dinyatakan: dipisahkan antara satu sama lain. Iman diidentikkan dengan akar dari sebuah pohon yang menopang tegaknya ajaran Islam. Ilmu bagaikan batang pohon

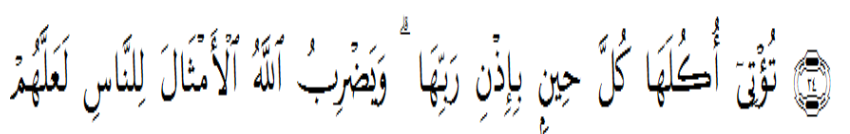
yang mengeluarkan dahan-dahan dan cabang-cabang ilmu pengetahuan.

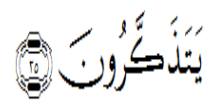

Terjemahannya:

24. Tidakkah kamu perhatikan bagaimana Allah telah membuat perumpamaan kalimat yang baik seperti pohon yang baik, akarnya teguh dan cabangnya (menjulang) ke langit,

25. pohon itu memberikan buahnya pada setiap musim dengan seizin Tuhannya. Allah membuat perumpamaanperumpamaan itu untuk manusia supaya mereka selalu ingat.

Ayat diatas menggambarkan keutuhan antara Iman, Ilmu dan Amal atau Aqidah, Syari'ah, dan Akhlak dengan menganalogikan bangunan Dinul Islam bagaikan sebatang pohon yang baik. Akarnya menghunjam ke bumi, batangnya menjulang tinggi kelangit, cabangnya atau dahannya rindang dan buahnya amat lebat. Ini merupakan gambaran bahwa antara pohon itu identik dengan teknologi. Iptek yang dikembangkan diatas nialinilai iman dan ilmu akan menghasilkan amal salih, bukan kerusakan alam.

\section{KESIMPULAN}

1. Islam sains dan teknologi adalah termasuk ayat-ayat Allah yang perlu digali dan dicari keberadaannya. Ayat-ayat Allah yang tersebar di alam semesta ini, dianugerahkan kepada manusia sebagai khalifah di muka bumi untuk diolah dan dimanfaatkan dengan sebaik-baiknya. Untuk itulah dibutuhkan kesadaran bagi tenaga - tenaga yang berprofesi langsung dalam dunia pendidikan agar senantiasa mengikuti tuntutan perkembangan zaman atau melakukan pengintegrasian Iptek 
dan Imtaq dalam proses pembelajaran untuk bekal dalam menjalankan hidup dan kehidupan bermasyarakat.

2. Pendidikan sendiri bukan hanya sekedar materi dan juga teori yang berlangsung di dalam sekolah atau perguruan tingi, namun juga berkaitan dengan norma, tata krama, sopan santun, hinga pembentukan pola pikir seseorang. Demikian pula halnya dalam hal penggunaan teknologi, mereka harus memiliki pemikiran dan norma serta etika dan tata krama dalam menggunakanya.

3. Teknologi itu diibaratkan dua mata pisau dalam segala aktivitas manusia, maksudnya adalah apabila pisau dipergunakan untuk menusuk orang berarti fungsinya untuk kejahatan tapi jika pisau ini dipergunakan sesuai fungsinya yang benar maka tentu saja akan bermanfaat. Demikian pula dengan teknologi yang semakin berkembang di jaman sekarang. Apabila dipergunakan secara bijak maka manfaatnya lebih banyak daripada mudharatnya. Oleh sebab itu jika iptek dipergunakan dan diimbangi dengan imtaq maka tentu hasilnya akan berbeda dengan menggunakan teknologi tanpa ada aturannya.

\section{DAFTAR PUSTAKA}

Ali, D, M, 2015, Pendidikan Agama Islam, cet. 13, Jakarta: Rajagrafindo Persada

Muhaimin, et, al, 2004, Paradigma Pendidikan Islam, cet. 2, Bandung: Remaja Rosdakarya

Zuhairini, 1995, Filsafat Pendidikan Islam, cet. 2, Jakarta: Bumi Aksara

AriefFurchan. H, Pengantar Penelitian Dalam Pendidikan, yogyakarta : Pustaka Pelajar,2004

Tafsir. A, 2005, Ilmu Pendidikan Dalam Persfektif Islam, Bandung: Remaja Rosdakarya

Shihab. Q, 2007, Membumikan AlQuran, Bandung: Mizan Media

Taufiq. I. M, 2006, Psikologi Islam, Jakarta: Gema Inzani

Daradjat. Z, 2008, Ilmu Pendidikan Islam, 2008, Jakarta: Bumi Aksara

Fuad bin Abdul Azis, A, 2008,Begini Seharusnya Menjadi Guru, cet. 1, Jakarta: Darul Haq.

Jamaluddin, D, Pebruary, 2013, Character Education in Islamic Perspective, International 
Journal of Scientific \& Tecnology Research Volume 2, Issue 2.

Kamaruddin A. S, 2012, Character Education and Social Behavior, journal of Education and Learning, vol.6(4) pp.223-230.

Lexy J, M, 2001,Metodologi Penelitian Kualitatif, cet. XIV, Bandung : PT' RemajaRosda Karya.

Lisyarti, R, 2012, Pendidikan Karakter dalam metode, Aktif, Inovtif, dan Kreatif, Penerbit: Erlangga

Masnur, M, 2011, Pendidikan Karakter Menjawab Tantangan Krisis Multidimensional,Cet. II, Jakarta: PT Bumi Aksara.

Muslich, M, 2011, Pendidikan Karakter (Menjawab Tantangan Krisis Multdimensional), cet. 1. Jakarta: Bumi Aksara.

Nurla Isna,A, 2011, Panduan Menerapkan Pendidikan Karakter di sekolah,Cet.1. Yogyakarta: Laksana.

Sanjaya, W, 2012, Strategi Pembelajaran (Berorientasi Standar Proses Pendidikan) (Penerbit: Kencana Premada Media Group, Jakarta).

Ulil Amri, S, 2012, Pendidikan Karakter Berbasis Al-Quran, cet. 1, Jakarta: Rajawali Press.
Undang-Undang No. 20 Tahun 2003, Tentang sistem Pendidikan Nasional.

Usman, H, 2011, Manajemen (Teori, Praktik, dan Riset Pendidikan) (Penerbit: Bumi Aksara, Jakarta Timur). 